\title{
A COMPARISON OF THE HEARTWOOD EXTRACTIVES OF PICEA GLAUCA AND PICEA ENGELMANNI ${ }^{1}$ \\ By G. M. BARTON and J. A. F. GARDNER
}

\author{
J. A. F. GARDNER
}

Born August 17th, 1919 at Nakusp, B.C. Educated in B.C. schools and University of British Columbia. B.A. (Honors Chemistry) 1940, M.A. (Chemistry) 1942. Ph.D. (Organic and Wood Chemistry) McGill 1944. Research Associate McGill 1944-45 on war research. Research chemist, Howard Smith Paper Mills, Cornwall, Ontario 1945-47. Head, Wood Chemistry, Forest Products Laboratory at Vancouver. Councillor and Fellow, Chemical Institute of Canada, member Technical Section C.P.P.A., TAPP1, American Chemical Society.

\section{GEORGE M. BARTON}

Born September 7, 1924 at Vancouver, B.C. Graduated from the University of B.C. with a B.A. (Honors Chemistry) 1946, with an M.A. (Chemistry) 1948. Lecturer with the Department of Chemistry at the University of B.C. 1948-1949. Research Chemist with the Wood Chemistry Section, Forest Products Laboratory at Vancouver, 1949-1956. Member of the Professional Institute of the Public Service of Canada and the Chemical Institute of Canada.

The wood of white spruce, Picea glauca (Moench) Voss, appears to be identical to that of Engelmann spruce, Picea Engelmanni Parry, under visual and microscopic examination. Because of their similar appearance, durability and strength properties, the two woods may be used interchangeably, however, for some purposes it is necessary to distinguish between them.

At present the only known way of differentiating between the two woods is based on examination of the foliage and cones of the trees from which a particular piece of wood is obtained. The cone scales of white spruce have smooth or at most very faintly toothed margins while those of Engelmann are mostly toothed. The method is, of course, far from satisfactory for lumber identification purposes. Futhermore, since the ranges of the species overlap and hybridization is believed to occur, the identification is never certain.

In wood identification it has sometimes been possible to make use of chemical tests as aids to the usual physical methods. Stearns (1) has reported that white oak can be distinguished from red oak on the basis of the different colors developed when the two are painted with diazotized benzidine solution. Isenberg and Buchanan (2) examined the color reaction to a methanol-hydrochloric acid solution for the wood of 277 species of 123 genera in 56 families, mostly American. In some genera, all the species examined gave a purple color but in some such as Acer and Quercus there were exceptions which they suggested might be made use of as aids to identification. In the genus Acer, all the species examined (12 in number) except box elder, Acer negundo, gave a purple color.

\footnotetext{
${ }^{1}$ A contribution from the Vancouver Laboratory, Forest Products Laboratories of Canada, a Division of the Forestry Branch, Department of Northern Affairs and National Resources. Received for publication July 20, 1956.
} 
A chemical method of differentiation depends on there being a difference in the composition of the extractive components of the woods being tested. While most of the methods presently available were originally developed by trial and error a detailed knowledge of the composition of the extractives of the species concerned should, where a difference occurs, sometimes allow the design of a logical chemical test.

The modern technique of paper partition chromatography is eminently suited to examining, both qualitatively and quantitatively, the composition of complex mixtures of organic chemicals such as occur in the extractive components of wood. By use of the appropriate modifications of this technique, it is possible to detect in a short time the presence of small amounts of various minor components which could not be isolated by ordinary means. Lindstedt (3) has applied the technique with success to the detection of twelve phenolic constituents in the extractives of the heartwood of 48 pinus species. In this laboratory, use of the technique in a preliminary examination of the extractives of western conifers (4) showed that there was a difference between the phenolic extractives of western hemlock (Tsuga heterophylla) and mountain hemlock (Tsuga canadensis) which might, if the need arose, be used to derive a chemical method of differentiation. This result suggested that the technique might be useful in determining if any difference existed between the extractive components of white and Engelmann spruce. It was thought that, if a significant consistent difference were found, then a simple chemical test, applicable in the field, might be developed.

Preliminary work on the spruces in 1950 indicated that any differences in the extractive component might be slight and that extensive examination of reliable samples was required. Suitable samples were obtained, the Engelmann samples being from Bend, Oregon, and Minturn, Colorado, and the white spruce samples from Fort Yukon, Alaska, and Petawawa, Ontario.2

Solutions of the heartwood extractives were prepared by extracting finely ground samples with the following solvents: water, acetone, ethyl ether, chloroform, and ethyl acetate. Each of the extracts was then examined thoroughly by means of paper partition chromatography at $23^{\circ} \pm .5^{\circ}$ using a variety of developing solvent systems and detecting reagents on Whatman No. 1 paper. These, listed in Table 1, included combinations known to be useful in separating phenolic and also carbohydrate substances. In each case, the paper chromatograms were examined under ultraviolet light before being sprayed with detecting reagent.

No consistent significant differences were found between the extracts prepared from Engelmann and white spruce samples. The presence of at least five phenolic components in the acetone extractive of both species was detected. No attempt to identify the individual components was made. While the relative concentration of these components varied between the two species, and also with the solvent used, similar variations were also evident between different samples of the same species. These results suggest that the heartwood

These samples were received through the courtesy of the Pacific Northwest, the Intermountain, and the Rocky Mountain Forest and Range Experiment Stations of the U.S. Forest Service and Mr. E. H. Garman of the British Columbia Forest Service. 
extractives of the two woods are very similar in respect to phenolic and carbohydrate components and provide little encouragement to search further for a simple chemical method of differentiating between the two species.

\section{TABLE I}

Solvent Systems and Detecting Reagents Used in Paper Chromatographic Examtnation of Spruce HearTwood EXtractives

\section{Developing Solvent}

Water saturated with carbon dioxide, $\mathrm{pH} 4.2$

Butanol, ethanol, water, ammonium hydroxide $(45,5,49,1)$

Butanol, water, acetic acid $(40,50,10)$

Benzene, ligroin, methanol, water $(50,50,1,50)$

Methyl ethyl ketone, water $(4,1)$ - used water phase

Methanol, chloroform, ligroin, water $(1,2,7,5)$

Boric acid solution $(1 \mathrm{~N})$, saturated carbon dioxide atmosphere

\section{Detecting Reagents}

$1 \%$ aqueous solution of freshly prepared ferric-ferricyanide.

Bis-diazotized benzidine.

Aniline trichloracetate.

\section{REFERENCES}

1. STEARNS, J. L. Distinguishing red oak from white oak by chemical color reaction. Southern Lumberman 184, 2306, 50 (1952).

2. ISENBERG, I. H. and BUCHANAN, M. A. Color reaction of wood with methanolhydrochloric acid. J. For. 43, 888 (1945).

3. LINDSTEDT, G. and MISIORNY, A. Constituents of pine heartwood XXV-investigation of 48 pinus species by paper-partition chromotography. Acta Chem. Scand. 5, 121-128 (1951).

4. BARTON, G. M., EVANS, R. S. and GARDNER, J. A. F. Paper chromatography of phenolic substances. Nature 170, 249-250 (1952). 